\title{
Occurrence of Major and Minor Brain Injuries in Facial Bone Fractures
}

\author{
Abul Kalam Md. Faruq ${ }^{1}$, Rowshan Afrooz ${ }^{2}$, Md. Shahidul Islam³, Shyamal Kumar
}

\begin{abstract}
Background \& objective: Road traffic accident (RTA), now a days, has become a common event worldwide. As face is the most exposed part of the body, is most at risk of sustaining trauma in RTA. However, there is paucity of information regarding the relationship between head injuries and facial trauma. A number of reviews have looked at brain injuries in patients with facial fractures. But these reviews failed to differentiate between major and minor brain injuries. Moreover, most studies were retrospective and based upon large trauma registries, which tend to preselect patients with multiple trauma and capture only major brain injuries. The incidence of minor brain injuries and concussion in this population is thus overlooked. This study was aimed to find the proportion of major and minor brain injuries in patients with facial bone fracture.
\end{abstract}

Materials \& Methods: This cross-sectional study was carried out in patients with facial bone fractures who attended at outpatient clinic, hospital ward of the Department of Oral and Maxillofacial Surgery, Dhaka Dental College Hospital, Dhaka, Neurosurgery Department, Emergency Department of Intensive Care Unit of Dhaka Medical College Hospital, Dhaka over a period of 2 years from January 2012 to December 2013. Only the patients of first encounters were included in the study. Patients referred from other centers with facial bone fracture were excluded. A total of 150 such patients were enrolled in the study. To assess and communicate the extent of an unconscious patient's injury rapidly Glasgow Coma Scale (GCS) was used. The outcome variable was brain injury (major and minor).

Result: Majority ( $80 \%$ ) of the patients was male with mean age of the patients being 25 years (range: from 4 - 80 years). The most common mechanism of injury in the present study was road-traffic accident $(60 \%)$, followed by assault ( $20 \%)$, fall from height (12\%), crash (6\%) and blast trauma ( $2 \%)$. Nearly half $(46 \%)$ of the patients had multiple facial bone fractures. Over $10 \%$ of the patients received Zygomatico-maxillary complex fracture. Mandible fracture and frontal bone fracture each accounted for $7.3 \%$. Nasal bone fracture was $6.7 \%$, isolated maxilla fracture was $5.3 \%$, Le Fort I fracture was $4.7 \%$ and orbital floor fracture was $4.0 \%$. The Glasgow coma score 12 or below 12 was found in $52 \%$ cases and loss of consciousness and perievent amenesia were observed in 54\% and 56\% cases respectively. The major and minor brain injuries were found in $52 \%$ and $32 \%$ cases respectively together comprising an occurrence of $84 \%$ in facial bone fractures. Male patients, receiving trauma through RTA and multiple facial bones fractures were significantly associated with brain injury $(p=0.019, p<0.001, p=0.001$ respectively). However, mandible and nasal bone fractures were less prone to be associated with brain injury in ( $p=0.001$ and $p<0.001$ respectively).

Conclusion: The study concluded that majority of the patients with facial bone fractures have had concomitant brain injuries. Male patients, receiving trauma through RTA and multiple fractures of the facial bones are more prone to be associated with brain injury than females, receiving injury through mechanisms other than RTA and isolated facial bone fractures.

Key words: Facial bone fracture, major and minor brain injuries.

\section{Authors' information:}

${ }^{1}$ Dr. Abul Kalam Md. Faruq, BDS, MS (OMS), Assistant Professor, Oral \& Maxillofacial Surgery, Dhaka Dental College, Dhaka.

${ }^{2}$ Dr. Rowshan Afrooz, MBBS, MS (Obs \& Gyne), Assistant professor, Obstetrics and Gynaecology, Nightingle Medical College, Sirajgonj.

${ }^{3}$ Dr. Md. Shahidul Islam, MBBS, FCPS (Surgery), Junior Consultant, 250 Bed Shaheed Sheikh Abu Naser Specialized Hospital, Khulna.

${ }^{4}$ Dr. Shyamal Kumar, Assistant professor, Oral \& Maxillofacial Surgery, Dhaka Dental College, Dhaka.

Correspondence: Dr. Abul Kalam Md. Faruq, Phone: +8801552327534 E-mail:dr.akmfaruq@yahoo.com 


\section{Introduction:}

The facial skeleton is one of the most complex arrangements of curving bony structures in the body and consists of bones of the mandible, maxilla, zygoma, bony walls of the nasal cavities, paranasal sinuses and orbit.1,2 This, being the most exposed part of the body, is particularly prone to trauma. ${ }^{3}$ The anatomical specificity of face provides protection to important vital organs such as the brain and eyes and others like the upper part of the digestive and respiratory systems..$^{1,2}$ Patients with maxillofacial trauma are at increased risk for head injuries due to close anatomic proximity of the facial skeleton and cranium. Varying rates of head injuries associated with maxillofacial fracture (as high as $86 \%$ ) have been reported in prior studies. ${ }^{4,5}$

Maxillofacial trauma is presented in accident and emergency department of the hospital as isolated injuries or part of polytrauma, ${ }^{6}$ though the risk of head trauma is significantly increased in multiple facial bone fractures. ${ }^{7}$ Cranial injury has been found to be the most common accompanying organ injury in patients with maxillofacial trauma..$^{8,9}$ This includes head traumas, intracranial hemorrhages, closed head traumas (brain contusion or laceration) or skull fracture. Generally, the presence of emesis, vomiting, loss of consciousness, or a low Glasgow Coma Scale (GCS) score are important findings for suspicion of a cranial injury. However, head trauma may be seen without the presence of these findings. Although major brain injuries are commonly recognized in patients, there is limited information on the incidence of minor brain injuries, despite their potential morbidity and mortality. ${ }^{10}$ Prompt determination of head injury in patients with maxillofacial injuries is crucial for improving patient survival and recovery. ${ }^{\text {? }}$

Presence of head trauma in patients with maxillofacial trauma may be a life-threatening condition. ${ }^{11}$ The patients of minor brain injuries or concussion may also be at risk for "second impact syndrome", a life-threatening swelling of the brain that occurs when a second concussion occurs shortly after the first one.12,13 Experience shows that many patients with facial fractures complain of symptoms associated with minor brain injuries and remain unexamined. The healthcare providers who initially assess the patients of maxillofacial trauma should examine them in terms of intracranial injury, which might increase the morbidity and mortality. ${ }^{7}$ A number of reviews have looked at brain injuries in patients with facial fractures. But these reviews failed to differentiate between major and minor brain injuries. Moreover, the studies were generally retrospective and based upon large trauma registries, which inherently preselected patients with multiple trauma and capture only major brain injuries. The incidence of minor brain injuries and concussion in this population has thus been ignored. Thus, the present study intended to find the proportion of major and minor brain injuries in patients with facial bone fracture would be of utmost value for the personnel concerned with diagnosing and treating the patients with facial bone fractures and brain injuries.

\section{Materials and methods:}

This cross-sectional study was carried out on patients with facial bone fractures who attended at the Outpatient Clinic, Hospital Ward of the Department of Oral and Maxillofacial Surgery, Dhaka Dental College Hospital, Dhaka \& Neurosurgery Department, Emergency Department, Intensive Care Unit of Dhaka Medical College Hospital, Dhaka over a period of 2 years between January 2012 to December 2013. Only the patients of first encounters fulfilling the enrolment criteria were included in the study. Patients referred from other centers with facial bone fracture were excluded. A total of 150 such patients were enrolled in the study. To evaluate the extent of an unconscious patient's injury rapidly, Glasgow Coma Scale was used, which was first introduced by Teasdale and Jennett. ${ }^{14}$ The GCS provides a reproducible index of neurologic status based on numerical values that are ascribed as eye opening, best verbal response and best motor response, although it is not suitable for detailed neurologic examination. 
Although GCS is widely accepted and valuable, accurate assessment of the patients with this tool can be difficult in the intubated patients, the patients who had suffered an injury to cervical spinal cord or the orbit, the young child without appropriately developed verbal skills and in the substance abused patients and, as such, patients with these characteristics were excluded. Generally, the presence of emesis, vomiting, loss of consciousness, or a low GCS score are important findings for suspicion of a cranial injury. The score ranges from $3-15$, where 3 indicate deep coma or brain death and 15 indicates minor brain injury with fully awake patients. The main outcome variables were major brain and minor brain injuries. Major brain injury was defined as an initial GCS score of 12 or less than 12 or a documented intracranial injury on computed tomography (CT) or magnetic resonance imaging (MRI). Minor brain injury was defined as GCS score of 13 or 14 or any documented loss of consciousness or peri-event amnesia. ${ }^{14,15}$ Information regarding age, sex, location of first assessment, time of initial assessment after event, mechanism of injury and associated injury were obtained for each subject. The facial bone fractures were diagnosed by clinical assessment, CT \& other radiological investigations like Orthopantomogram (OPG), X-ray skull, P/A view, occipito-mental view, PNS, submento-vertex view etc. Data were processed and analyzed using SPSS (Statistical Package for Social Sciences), version 17 . The test statistics used to analyze the data were descriptive statistics, Chi-square $\left(\chi^{2}\right)$ or Fisher's Exact Probability Test and Unpaired t-Test. The level of significance was set at $5 \%$ and $p<$ 0.05 was considered significant.

\section{Results}

Over one-third of the patients were $<20$ years and $24 \% 20$ - 30 years old. The rest (38\%) was $30>30$ years old. The patients' age ranged from 4 - 80 years with a mean age being 25 years. Eighty percent of the patients were male and the rest female (male to female ratio $4: 1$ ). Nearly three-quarters $(74 \%)$ of the patients were first assessed at hospital ward after admission, 14\% in ICU, $10 \%$ in Emergency Department and a few $(2 \%)$ in surgery clinic. Over one-quarter (28\%) was first assessed within 6 hours of occurrence of the accident, $14 \%$ between $7-12$ hours, 22\% between $12-24$ hours and the rest after $\geq 24$ hours. The median time to initial assessment was 14 hours (range: 1 hour to 3 months). Sixty percent of the patients received facial trauma from road-traffic accident, $20 \%$ from assault, $12 \%$ fall from height, $6 \%$ from crash and $2 \%$ from blast trauma (Table I). Nearly half (46\%) of the patients had multiple facial bone fractures. Over $10 \%$ of the patients received Zygomaticomaxillary complex fracture. Mandible fracture and frontal bone fracture each accounted for $7.3 \%$. Nasal bone fracture was $6.7 \%$, isolated maxilla fracture $5.3 \%$, Le Fort I fracture $4.7 \%$ and orbital floor fracture $4.0 \%$. More than half (52\%) have had skull fracture and $22 \%$ extremity fracture. Spine, ribs and multiple fractures each was $8 \%$. In terms of types of closed-head injuries, nearly half of the patients had subarachnoid haemorrhage, $16 \%$ haemorrhagic contusion, $10 \%$ intraventricular haemorrhage, $8 \%$ subdural hematoma and another $8 \%$ oedema. Epidural hematoma and pneumoencephalus each was 6\% (Table II). Over half $(54 \%)$ of the patients had loss of consciousness and perievent amenesia (56\%). Half of the patients (52\%) had GCS score 12 or $<12$ and half (48\%) 13 - 15 with mean GCS score being 10.5 . Some $4 \%$ patients needed intubation and $12.0 \%$ needed neurosurgical intervention (Table III). Over half (52\%) had major brain injury, 48(32\%) minor brain injury and $24(16 \%)$ were without any evidences of brain injury (Fig 1).

The patients of brain injury were a bit younger than those who did not sustain brain injury, although the difference was not statistically significant ( $p=0.557)$. Males tend to be associated with brain injury more often than their female counterparts ( $p=0.019$ ) (Table IV). The data revealed that the more the delay in initial assessment, the more is the chance of brain injury $(p=0.082)$. Of the mechanisms of injury, the RTA 
patients are significantly prone to be associated brain injury than the injuries caused by other mechanisms of $(p<0.001)$ (Table $V)$. There was significantly less chance of having brain injury in mandible and nasal bone fractures $(p=0.001$ and $p<0.001$ respectively). Zygomatico-maxillary complex, orbital floor, frontal bone fracture all were considerably higher in patients with brain injury. Le Fort I, Le Fort II and Le Fort III fracture were solely present in patients with brain injury. Multiple facial bone fracture was significantly higher in patients with brain injury $(94.2 \%)$ than that in patients without brain injury $(5.8 \%)$ $(p=0.001)$ (Table VI).

\begin{tabular}{|c|c|c|}
\hline Demographic characteristics & Frequency & Percentage \\
\hline \multicolumn{3}{|l|}{ Age (Years)* } \\
\hline$<20$ & 57 & 38.0 \\
\hline $20-30$ & 36 & 24.0 \\
\hline $30-40$ & 20 & 13.3 \\
\hline $40-50$ & 19 & 12.7 \\
\hline$\geq 50$ & 18 & 12.0 \\
\hline \multicolumn{3}{|l|}{ Sex } \\
\hline Male & 120 & 80 \\
\hline Female & 30 & 20 \\
\hline \multicolumn{3}{|l|}{ Location of first assessment } \\
\hline Surgery clinic & 3 & 2 \\
\hline Emergency department & 15 & 10 \\
\hline ICU & 21 & 14 \\
\hline Hospital ward & 111 & 74 \\
\hline \multicolumn{3}{|c|}{ Time to initial assessment (hours) ${ }^{* *}$} \\
\hline$<6$ & 42 & 28.0 \\
\hline $7-12$ & 21 & 14.0 \\
\hline $12-24$ & 33 & 22.0 \\
\hline $24-48$ & 12 & 8.0 \\
\hline $48-72$ & 9 & 6.0 \\
\hline$\geq 72$ & 33 & 22.0 \\
\hline \multicolumn{3}{|l|}{ Mechanism of injury } \\
\hline RTA & 90 & 60.0 \\
\hline Assault & 30 & 20.0 \\
\hline Fall & 18 & 12.0 \\
\hline Blast Trauma & 3 & 2.0 \\
\hline Crash & 9 & 6.0 \\
\hline
\end{tabular}

${ }^{*}$ Mean age $=(25.0 \pm 2.8)$ years; range $=(4-80)$ years.

**Median: 14 hours; range: 1 hour -3 months
TABLE II : Distribution of patients by facial bone fractures pattern $(n=150)$

\begin{tabular}{|c|c|c|}
\hline Facial bone fractures & Frequency & Percentage \\
\hline \multicolumn{3}{|l|}{ Pattern of facial bone fractures } \\
\hline Mandible & 11 & 7.3 \\
\hline Nasal & 10 & 6.7 \\
\hline Zygomatic arch & 4 & 2.7 \\
\hline Isolated maxilla & 8 & 5.3 \\
\hline Orbital floor & 6 & 4.0 \\
\hline Maxillary sinus & 3 & 2.0 \\
\hline Frontal bone & 11 & 7.3 \\
\hline Le Fort I & 3 & 4.7 \\
\hline Le Fort II & 4 & 2.7 \\
\hline Le Fort III & 3 & 2.0 \\
\hline Zygomatico-maxillary complex & 18 & 12.0 \\
\hline Multiple & 69 & 46.0 \\
\hline \multicolumn{3}{|l|}{ Associated injury } \\
\hline Spine & 12 & 8.0 \\
\hline Extremity & 33 & 22.0 \\
\hline Thoracic & 12 & 8.0 \\
\hline Skull fracture & 78 & 52.0 \\
\hline Multiple Injuries & 12 & 8.0 \\
\hline \multicolumn{3}{|l|}{ Types of closed-head injuries* } \\
\hline Subarachnoid haemorrhage & 36 & 24.0 \\
\hline Haemorrhagic contusion & 24 & 16.0 \\
\hline Intraventricular haemorrhage & 15 & 10.0 \\
\hline Subdural hematoma & 12 & 8.0 \\
\hline Odema & 12 & 8.0 \\
\hline Epidural hematoma & 9 & 6.0 \\
\hline Pneumoencephalus & 9 & 6.0 \\
\hline Midline shifts & 3 & 2.0 \\
\hline Basal injury & 3 & 2.0 \\
\hline
\end{tabular}

*Total number does not correspond to the total number ofcases due to different types of closed-head injuries in the same case and there were no closed head injuries in some cases.

\begin{tabular}{|c|c|c|}
\hline \multicolumn{3}{|c|}{$\begin{array}{l}\text { TABLE III : Stratification of patients by clinical neurological } \\
\text { findings }\left(n=150^{* *}\right)\end{array}$} \\
\hline Clinical neurological findings & Frequency & Percentage \\
\hline Loss of consciousness & 81 & 54.0 \\
\hline Perievent amnesia & 84 & 56.0 \\
\hline \multicolumn{3}{|l|}{ Glasgow Coma Scale (GCS) score* } \\
\hline$\leq 12$ & 78 & 52.0 \\
\hline$>12$ & 72 & 48.0 \\
\hline Need for intubation & 6 & 4.0 \\
\hline Neurosurgical intervention & 18 & 12.0 \\
\hline
\end{tabular}




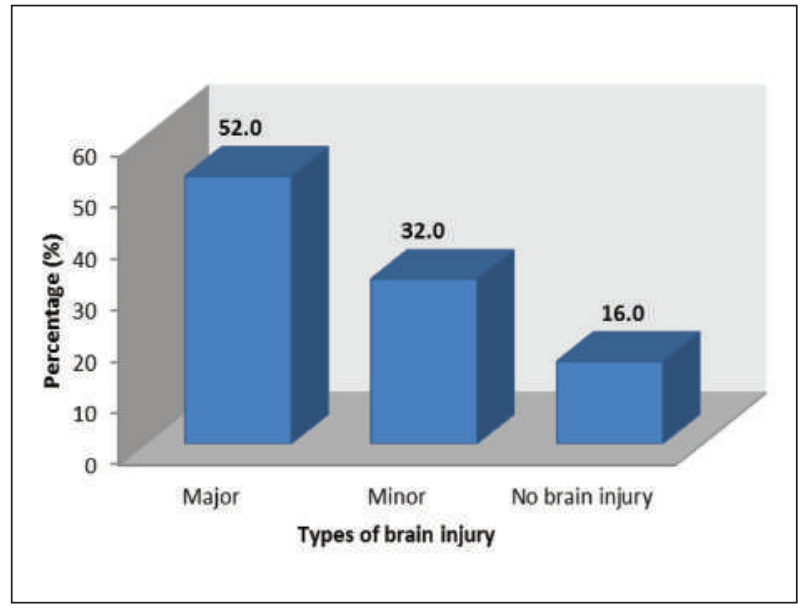

Fig 1. Distribution of patients by status of brain injury $(n=150)$

\begin{tabular}{|c|c|c|c|}
\hline \multicolumn{4}{|c|}{$\begin{array}{l}\text { TABLE IV : Association between demographic characteristics } \\
\text { and brain injury }\end{array}$} \\
\hline \multirow{2}{*}{$\begin{array}{l}\text { Demographic } \\
\text { characteristics }\end{array}$} & \multicolumn{2}{|c|}{ Brain Injury } & \multirow[b]{2}{*}{ p-value } \\
\hline & $\begin{array}{c}\text { Yes } \\
(n=126)\end{array}$ & $\begin{array}{c}\text { No } \\
(n=24)\end{array}$ & \\
\hline Age\# & $29.4 \pm 19.6$ & $32.0 \pm 23.3$ & 0.557 \\
\hline \multicolumn{4}{|l|}{ Sex* } \\
\hline Male & 105 (83.3) & $15(62.5)$ & \multirow{2}{*}{0.019} \\
\hline Female & 21 (16.7) & $9(37.5)$ & \\
\hline
\end{tabular}

Figures in the parentheses indicate corresponding \%; *Chi-squared Test $\left(\chi^{2}\right)$ was done to analyze the data. \# Data were analyzed using Unpaired t-Test and were presented as mean \pm SD.

TABLE V : Influence of delay in initial assessment and mechanism of injury on brain injury

\section{Time of initial}

assessment and

injury mechanism*

Time of initial assessment (hours)

$\begin{array}{lccc}<12 & 48(38.1) & 15(62.5) & \\ 12-24 & 30(23.8) & 3(12.5) & 0.082 \\ \geq 24 & 48(38.1) & 6(25.0) & \\ \begin{array}{l}\text { Mechanism of injury } \\ \text { RTA }\end{array} & & & \\ \text { Assault } & 84(66.7) & 6(25.0) & \\ \text { Fall } & 15(11.9) & 15(62.5) & <0.001 \\ \text { Blast and machinery } & 15(11.9) & 3(12.5) & \\ \text { trauma } & & & \\ & 12(9.5) & 0(0.0) & \end{array}$

Figures in the parentheses indicate corresponding \%; ${ }^{*}$ Chi-squared Test $\left(\chi^{2}\right)$ was done to analyze the data.
TABLE VI : Association between facial bone fracture patterns and brain injury

\begin{tabular}{|c|c|c|c|}
\hline \multirow{2}{*}{$\begin{array}{l}\text { Facial fracture } \\
\text { pattern* }\end{array}$} & \multicolumn{2}{|c|}{ Brain Injury } & \multirow{2}{*}{$p$-value } \\
\hline & Yes & No & \\
\hline Mandible* $^{*}(n=11)$ & $4(36.4)$ & $7(63.6)$ & 0.001 \\
\hline Nasal $^{*}(n=10)$ & $3(30.0)$ & $7(70.0)$ & $<0.001$ \\
\hline Zygomatic $\operatorname{arch}^{\#}(n=4)$ & $3(75.0)$ & $1(25.0)$ & 0.506 \\
\hline Isolated maxilla* $(n=8)$ & $7(87.5)$ & $1(12.5)$ & 0.624 \\
\hline Maxillary sinus $(n=3)$ & $3(100.0)$ & $0(0.0)$ & 0.590 \\
\hline Orbital floor* $(n=6)$ & $6(100.0)$ & $0(0.0)$ & 0.604 \\
\hline Frontal bone* $(n=11)$ & 10(90.9) & $1(9.1)$ & 0.824 \\
\hline Le Fort $I^{*}(n=3)$ & $3(100.0)$ & $0(0.0)$ & 0.590 \\
\hline Le Fort $I^{\#}(n=4)$ & $4(100.0)$ & $0(0.0)$ & 0.494 \\
\hline Le Fort III" $(n=3)$ & $3(100.0)$ & $0(0.0)$ & 0.590 \\
\hline \multicolumn{4}{|l|}{ Zygomatico-maxillary } \\
\hline complex $^{\#}(n=18)$ & $15(83.3)$ & $3(16.7)$ & 0.579 \\
\hline Multiple* $^{*}(n=69)$ & $65(94.2)$ & $4(5.8)$ & 0.001 \\
\hline
\end{tabular}

Figures in the parentheses indicate corresponding \%;

\# Fisher's Exact Test was done to analyze the data;

*Chi-squared Test $\left(\chi^{2}\right)$ was done to analyze the data.

\section{Discussion:}

The present study was intended to highlight the pattern of facial bone fractures and the brain injuries associated with them. The study demonstrated that majority $(80 \%)$ of the patients was male with mean age of the patients being 25 years (range: $4-80$ years). Consistent with our findings Grant and colleagues $^{10}$ demonstrated that most patients $(79 \%)$ of facial trauma are male with a wider age range from 6 to 88 years (average being 34.1 years), peaking in the teens and twenties, with $60 \%$ of the sample between the ages of 10 and 39 years. Nearly two-thirds (64\%) of the patients were evaluated within 24 hours of the accident and the rest $36 \%$ after 24 hours. The earliest initial assessment was within an hour and delayed assessment was as long as 3 months. In Grant's study $72 \%$ were seen by the craniofacial surgery team within the first week of their injury, one-third within 24 hours but the delay between injury and the first assessment was as long as 4 months bearing consistency with the findings of the present study. The most common mechanism of injury in the 
present study was road-traffic accident (60\%), followed by assault (20\%) fall from height (12\%), crash (6\%) and blast trauma (2\%). Sharply contrasting with these findings, Grant ${ }^{10}$ showed that most common mechanism of injury was assault $(33 \%)$, followed by falls $(31 \%)$, and motor vehicle accidents (21\%). Together, these 3 mechanisms accounted for $85 \%$ of the maxillofacial trauma patients which in our study comprised $82 \%$ of the patients.

About half $(46 \%)$ of the patients received multiple facial bone fractures. In terms of associated injuries more than half (52\%) had skull fracture and $22 \%$ extremity fracture. The major and minor brain injuries associated with facial bone fracture were $52 \%$ and $32 \%$ respectively together comprising a brain injury of $84 \%$. In a recent study ${ }^{10}$ the most common fracture pattern was nasal fracture, followed by mandibular fracture, but 11 different fracture types were identified, including multiple facial bone fractures. Two-thirds of the patients had an associated major (29\%) or minor (38\%) brain injury, with $35 \%$ having documented findings on MRI, including intracranial hemorrhage and visible contusions. The reported incidence of associated brain injury varies much more widely in the literature, from 5 - 89\%.2,4,9 While Ravindran ${ }^{16}$ reported a much higher incidence of brain injury $(93 \%)$, Zandi and Hoseini ${ }^{17}$ reported a much lower incidence (23.3\%). Isik et $\mathrm{al}^{7}$ showed an even lower incidence of cranial injury (14.4\%) in patients with maxillofacial trauma. Alvi et $\mathrm{al}^{8}$ showed a moderate incidence of head injury $(43.7 \%)$ in facial fracture patients and 11 of them died of neurologic complications. The reason of such wide variation in incidence of brain injury might be that most of these studies are retrospective in nature and fail to clearly define "brain injury" or differentiate between major and minor brain injuries. The concern with these studies is that large trauma registries tend to preselect patients with multiple trauma and major brain injury. Unless specific information was documented related to minor brain injury, the incidence may have been erroneously low. The risk of head injury has been estimated to be 3.4 fold lower among patients with single facial bone fractures and risk increases significantly with multiple facial bone fractures. The risk of head trauma also increases with fractures of the nasal bone, maxillary bone and frontal region fractures. Perry et al ${ }^{18}$ found that facial trauma with or without sight threatening complications may arise following isolated injury, or it may be associated with significant injuries elsewhere. Life and sight threatening complications may also occur following apparently trivial injuries, which may not immediately be evident on arrival in the resuscitation or emergency setting.

Spine and ribs fractures were rare in our study (each was $8 \%$ ). However, there is good evidence to suggest that patients with facial fractures are at high risk for associated cervical spine injuries, with the incidence varying from $0-9.6 \% .^{2,4,19-21}$ In terms of types of closed-head injuries, nearly one-quarter $(24 \%)$ of the patients had subarachnoid haemorrhage, $16 \%$ haemorrhagic contusion, $10 \%$ intraventricular haemorrhage, $8 \%$ subdural hematoma and another $8 \%$ oedema. Epidural hematoma and pneumoencephalus each was $6 \%$. Closed head injury or brain injury affects at least one in five patients who sustain facial fractures. ${ }^{2,22}$ The effect can range from simple loss of consciousness to coma and death.

Certain characteristics of the patients, mechanism of injury and facial bone fracture of the patients were more often found to be associated with brain injury. Accordingly males, receiving facial trauma through RTA and multiple fractures of the facial bones were significantly associated with brain injury than females, receiving injury through mechanism other than RTA and isolated facial bone fracture. However, mandible \& nasal bone fractures were less prone to be associated with brain injury ( $p=0.001$ and $p<0.001$ respectively). Consistent with these findings Isik et al. ${ }^{7}$ demonstrated that the risk of head trauma significantly increased in multiple (2 or more) facial bone fractures $(p<0.001)$. There are potential risks to the patient if the diagnosis of minor head injury is missed. Symptoms such as impaired memory and concentration and persistent headaches can often limit function and safe return to work. In addition, patients may be at risk for second impact syndrome. If the severity and 
consequences of concussion are not recognized, then patients may have been inadequately advised regarding follow-up and return to sports, work, and other potentially dangerous or problematic activities. $^{12}$

This study has several limitations, foremost being the relatively small sample size compared to the calculated one restricting further subgroup analysis, such as an analysis to determine which non facial injuries might be predictive of brain injury. The samples were obtained from two centres only which limits generalization of the findings to the reference population. A further limitation is that there is no widely accepted diagnostic tool for identifying minor brain injury, and the definitions used in this study might be contested. As there is paucity of epidemiologic data from Bangladeshi population, this study was primarily undertaken to look at the pattern of facial fracture, occurrence of major and minor brain injuries and treatment modalities at our centre offering maxillofacial trauma services. However, the data generated from the study may provide baseline information to guide in prevention and proper planning of maxillofacial trauma care in our hospital and in the region.

\section{Conclusion:}

It appears from the findings of the present study that majority of the patients with maxillofacial fracture have had concomitant brain injuries. Male patients, receiving trauma through RTA and multiple fractures of the facial bones are more prone to be associated with brain injury than females, receiving injury through mechanisms other than RTA and isolated facial bone fractures. Major brain injuries are detected at the initial assessment. But all minor brain injuries are not immediately diagnosed because of lack of signs and symptoms. The high incidence of closed head injury in the facial trauma population and the potential for mortality and neurologic morbidity make it a distinct concern for the practicing oral and maxillofacial surgeons. So all facial fracture patients should be constantly monitored to see the development of signs and symptoms of minor brain injuries in order to make an early diagnosis and ensure better management.

\section{References:}

1. Sing G, Mohammad S, Pal US, Hariram, Malkunje LR \& Sing N. Pediatric facial injuries: It's management. Natl J Maxillofac Surg 2011;2:156-62.

2. Haug RH, Prather J \& Indresano AT. An epidemiologic survey of facial fractures and concomitant injuries. J Oral Maxillofac Surg 1990;48:926-32.

3. Oji C. Apr. jaw fractures in Enugu, Nigeria. 1985-95. Br J Oral Maxillofac Surg 1999;37(2):106-109.

4. Pappachan B \& Alexander M. Correlating facial fractures and cranial injuries. J Oral Maxillofac Surg 2006;64: 1023-29.

5. Hayter JP, Ward AJ \& Smith EJ. Maxillofacial trauma in severely injured patients. Br J Oral Maxillofac Surg 1991;29:370-3.

6. Nayyar MS \& Ekanayke MBK. Assessment of Maxillofacial Injuries. Pak Oral dental J 2001;21:12-18.

7. Isik D, Gonullu H, Karadas S, Kockaf AS, Keskin S, Garka MF et al. Presence accompanying head injury in patients with maxillofacial trauma. Ulus Trauma Acil Cerrahi Derg 2012;18(3):200-06.

8. Alvi A, Doherty $T$ \& Lewen G. Facial fractures and concomitant injuries in trauma patients. Laryngoscope 2003;113:102-6.

9. Mulligan RP \& Mahabir RC. The prevalence of cervical-spine injury, head injury, or both with isolated \& multiple craniomaxillofacial fractures. Plast Reconstr Surg 2010;126:1647-51.

10. Grant AL, Ranger A, Young GB \& Yazdani A. Incidence of major and minor brain injuries in facial fractures. $J$ Cranifac Surg 2012;23(5):1324-28.

11. Bouamra O, Wrotchford A, Hollis S, Vail A, Woodford M \& Lecky $\mathrm{F}$. Outcome prediction in trauma. Injury 2006;37:1092-7.

12. Alexander MP. Mild traumatic brain injury: pathophysiology, natural history \& clinical management. Neurology 1995;45:1253-60.

13. Heinze $\mathrm{HJ}$, Munte TF \& Gobiet W. Parallel and serial visual search after closed head injury: electrophysiological evidence for perceptual dysfunctions. Neuropsychologia 1992;30:495-514.

14. Teasdale G \& Jennett B. Assessment of coma and impaired consciousness - A practical scale. Lancet $1974 ; 2: 81-84$.

15. Bellner J, Jensen SM, Lexell J \& Romner B. Diagnostic criteria and the use of ICD-10 codes to define and classify minor head injury. J Neurolog Neurosurg Psychiatry 2003; 74:351-52. 
16. Ravindran V \& Ravindran NKS. Metaanalysis of maxillofacial trauma in the northern districts of kerala: One year prospective study. J Maxillofac Oral Surg 2011;10:321-27.

17. Zandi M \& Hoseini SSR. The relationship between head injury and facial trauma: a case control study. Oral Maxillofac Surg 2012;17(3):201-07.

18. Perry M, Dancey A, Mireskandari K, Oakley P, Davies S, Cameron M. Emergency care in facial trauma - A maxillofacial and ophthalmic perspective. Injury 2005; 36:875-96.

19. Carlin CB, Ruff G, Mansfeld CP \& Clinton MS. Facial fractures and related injuries: a ten-year retrospective analysis. J Craniomaxillofac Trauma 1998;4(2):44-48.
20. Lim LH, Lam LK, Moore MH, Trott JA \& David DJ. Associated injuries in facial fractures: review of 839 patients. Br J Plast Surg 1993;46:635-38.

21. Davidoff G, Jakubowski M, Thomas D \& Alpert M. The spectrum of closed-head injuries in facial trauma victims: incidence and impact. Ann Emerg Med 1998;17:6-9.

22. Conforti PJ, Haug RH \& Likavec M. Management of closed head injury in the patient with maxillofacial trauma. J Oral Maxillofac Surg 1993;51:298-303. 